Brazilian Journal

of Chemical

Engineering

\title{
SYNTHESIS, CHARACTERIZATION AND in vitro CYTOTOXICITY OF Acacia mearnsii PROANTHOCYANIDIN-LOADED PLGA MICROPARTICLES
}

\author{
Fábio dos S. Grasel ${ }^{1,2^{*}}$, Michele C. Behrens ${ }^{3}$, Débora Strassburger ${ }^{4}$, Sandra Einloft ${ }^{1,3}$, \\ Fernando M. Diz ${ }^{1}$, Fernanda B. Morrone ${ }^{5}$, Carlos R. Wolf ${ }^{2}$ and Rosane A. Ligabue ${ }^{1,3 *}$ \\ ${ }^{1}$ Pontifícia Universidade Católica do Rio Grande do Sul, Porto Alegre, RS, Brasil. E-mail: fsgrasel@gmail.com, \\ ORCID: 0000-0002-1380-0731; ORCID: 0000-0003-1364-0325; rligabue@pucrs.br, ORCID: 0000-0002-7086-8820 \\ ${ }^{2}$ TANAC S/A, Montenegro, RS, Brasil. \\ ${ }^{3}$ Pontifícia Universidade Católica do Rio Grande do Sul, Escola de Ciências, Porto Alegre, RS, Brasil. \\ ${ }^{4}$ Pontifícia Universidade Católica do Rio Grande do Sul, Escola Politécnica, Porto Alegre, RS, Brasil. \\ ${ }^{5}$ Pontifícia Universidade Católica do Rio Grande do Sul, Escola de Ciências da Saúde, Porto Alegre, RS, Brasil.
} ORCID: 0000-0002-2709-2801

(Submitted: March 19, 2017 ; Revised: January 10, 2018 ; Accepted: February 13, 2018)

\begin{abstract}
One of the highlighted areas in the development of new materials is the generation of micro- and nanoparticles as drug carriers which allow the progress in formulations with the ability to release active agents in a controlled way. The proanthocyanidins (PAC) extracted from the bark of the Black Wattle have stood out for their biological activities. However, most polyflavonoids have some features which limit their application in the pharmaceutical field, such as light fastness, low bioavailability of active agents, and unpleasant taste. In this context, this study aims to present the synthesis and characterization of PAC-loaded lactic-co-glycolic acid (PLGA) microparticles obtained by the multiple emulsion method. The incorporation of PAC into PLGA was successfully achieved with PAC encapsulation efficiency around $73 \%$. Spherical microparticles were obtained with a size distribution in the range of 0.6 to $2.4 \mu \mathrm{m}$. The presence of PAC modified the thermal properties of the PLGA matrix. The results of in vitro assays with Vero and T24 lineage celss showed that PLGA/PAC microparticles did not promote any effect on cell proliferation by MTT assay after $24 \mathrm{~h}$. The novel Acacia mearnsii proanthocyanidin-loaded PLGA microparticles have potential for application in biological systems. Keywords: Microparticle; Proanthocyanidins; PLGA; Acacia mearnsii; Drug carrier.
\end{abstract}

\section{INTRODUCTION}

Acacia mearnsii from Wild (Black Wattle) is a medium-sized tree of the Fabaceae family (Leguminosae), native to Australia. Their high productivity and rapid adaptation to different environmental conditions facilitate their introduction in different regions of the world (Grasel et al., 2016d; Menezes et al., 2014). The bark of this leguminous plant is well known for its high concentration of tannins (proanthocyanidins), a property that has aroused great economic interest. Vegetable tannins are plant extracts that have traditionally been used to tan leather (Grasel et al., 2016a).

The industrial production of Black Wattle's proanthocyanidin (PAC) is mainly used in applications such as tanning, wood adhesives and obtaining natural coagulant agents (Arbenz and Avérous, 2015; Garcia et al., 2016; Menezes et

\footnotetext{
* Corresponding authors: Fábio dos S. Grasel and Rosane A. Ligabue - E-mail: fsgrasel@gmail.com, rligabue@pucrs.br
} 
al., 2014). The tannin concentration in the Acacia mearnsii bark may reach values above $45 \%$ (w/w); however, this output may vary significantly according to the weather and pedological conditions of the growing site, plant morphology and the cultivation techniques used (Menezes et al., 2014).

Proanthocyanidins are oligomers constituted by the basic structure of flavan-3-ol condensed at $\mathrm{C} 4$ C6 and C4-C8 of the structure (Grasel and Ferrão, 2016; Grasel et al., 2016e; Pasch et al., 2001; Pizzi et al., 2012; Tondi et al., 2013; Venter et al., 2012) as shown in Figure 1.

Pasch et al. (2001) developed a method for determining the chemical structure of tannins by matrix-assisted laser desorption/ionization timeof-flight mass spectrometry (MALDI-TOF-MS). The authors concluded that the polymeric chains of Black Wattle tannins can exist as monomers to octamers and the molar weight can vary by 16 $\mathrm{Da}$, due to replacement of hydroxyl groups around the tannin structures (Fig. 1) (Grasel and Ferrão, 2016; Grasel et al., 2016e; Pasch et al., 2001; Pizzi et al., 2012; Reyer et al., 2016; Tondi et al., 2013; Venter et al., 2012).

The chemical composition of Black Wattle extracts was determined by Venter et al. (2012) using the electrospray ionization mass spectrometry (ESI-MS) technique. The authors showed that the Black Wattle extracts are mainly composed of dimers of catechin or gallocatechin and robinetinidol and trimers having two robinetinidol instead of one in their composition. The chemical structures found by the authors are in accordance with those cited in the literature (Fig. 1) (Botha et al., 1978; Botha et al., 1981; Drewes et al., 1967; Drewes and Roux, 1963; Hundt and Roux, 1978; Hundt and Roux, 1982; Roux and Maihs, 1960; Saayman and Roux, 1965; Viviers et al., 1983). In addition to technological applications, these compounds also exhibit interesting biological properties such as antioxidant (Olajuyigbe and Afolayan, 2011b; Shen et al., 2010), antitumor (Shen et al., 2010), antimicrobial (Olajuyigbe and Afolayan, 2011a; Olajuyigbe and Afolayan, $2012 \mathrm{~b}$ ), bacteriostatic (Olajuyigbe and Afolayan, 2012ab) and anti-inflammatory (Yoshihara et al., 2014).

Yoshihara et al. (2014) investigated the effect of PAC from Black Wattle on eclosion eggs and larvae mortality. Gastrointestinal parasitism in sheep causes numerous losses to farmers. The control is performed basically by the administration of synthetic anthelminthics which stimulate the
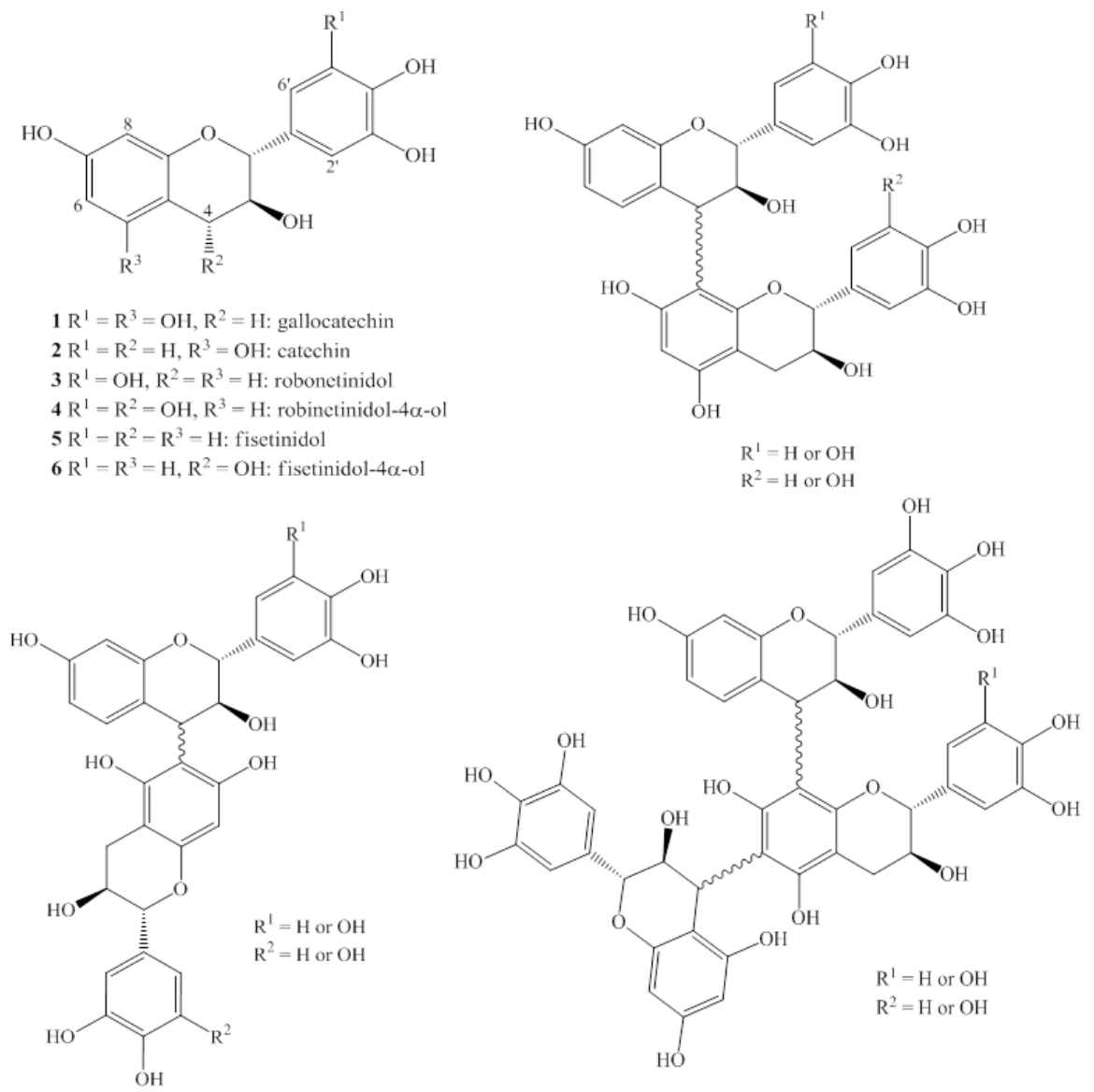

Figure 1. General structure of condensed tannins: polymerization of flavan-3-ol (catechin monomer). 
development of resistant parasites. The use of plants rich in tannins appears as a promising alternative in helminthes control in sheep. The larvicidal action observed in the in vitro study of Black Wattle PAC indicated an anthelminthic action presenting potential for its application in the alternative control of gastrointestinal nematodes of small ruminants (Yoshihara et al., 2014).

The natural tannins from plant sources as $\alpha$-amylase inhibitors have attracted great interest among researchers (Costa et al., 2008; Donkora et al., 2012; Du et al., 2012; Etxeberria et al., 2012; Kusano et al., 2010; Olmedo et al., 1987; Sarmadi et al., 2012; Wongsa et al., 2012; Xu et al., 2016). Human $\alpha$-amylases from both pancreatic and salivary origins have been widely studied for clinical and nutritional purposes because they are targets for drugs designed to treat some diseases such as diabetes and hyperlipidemia ( $\mathrm{Du}$ et al., 2012; Etxeberria et al., 2012).

Unfortunately, the use of these valuable natural compounds is limited, since they have low stability to light and heat, as well as tasting very astringent and bitter (Munin et al., 2011; Lu et al., 2016). To overcome these drawbacks, carrier systems have been developed, and this included micro- and nanocapsules that appear as a promising approach. Pool et al. (2012) synthesized lactic-co-glycolic acid (PLGA) nanoparticles for the entrapment and controlled release of quercetin and catechin. In vitro tests showed that the releases of these flavonoids are accelerated in acid medium and the inhibition of the action of free radicals and chelating properties were also improved.

In a recent study of flavonoids encapsulation, Kumar et al. (2015) prepared, by nanoprecipitation method, polycaprolactone (PCL) nanocapsules with quercetin. They observed that quercetin remained trapped in the nanoparticles with a release time greater than $48 \mathrm{~h}$. This result shows that an encapsulation system may facilitate protection and quercetin release or increase the bioavailability of pharmaceutical or food products.

In another study, Barras et al. (2009) synthesized and characterized two new lipid nanocapsules of flavonoids (quercetin and (-)-epigallocatechin3 -gallate) with a highly efficient encapsulation $(>95 \%)$ and an increase in the stability of the encapsulated product was recorded.

Pandey et al. (2015) synthesized poly(lactic acid) (PLA) nanoparticles with quercetin by using an emulsified nanoprecipitation technique with approximately $62 \%(\mathrm{w} / \mathrm{w})$ of incorporation efficiency. An in vitro cytotoxicity study led to death of around $50 \%$ of breast cancer cells in two days at $100 \mu \mathrm{g} / \mathrm{mL}$ of drug concentration (quercetin), while around $40 \%$ of cells were destroyed in
5 days with the quercetin nanoparticles. These results confirm the anticancer efficacy of quercetin nanoparticles, revealing a novel vehicle for the treatment of cancer.

Despite the diversity of biological applications of Black Wattle proanthocyanidins described in the literature, as far as we know there is not any work carried out about the micro- or nanoencapsulation of these polyflavonoids with biodegradable polymers. Within this context, this work aims at the development and characterization of Black Wattle proanthocyanidin microspheres with a biodegradable polymer matrix by multiple emulsion process.

\section{MATERIALS AND METHODS}

\section{Preparation of the PAC/PLGA microparticles}

The microparticles with Acacia mearnsii proanthocyanidins (PAC powder, Tanac $\mathrm{S} / \mathrm{A}$ ) were obtained from the biodegradable polymer poly(lactic-co-glycolic acid) (PLGA, PURASORB PLG $8523 \AA$, Purac) by the multiple emulsion technique. In this work, it was opted for the multiple emulsion process, due to the high solubility of proanthocyanidins in water, besides the low solubility of PLGA. Initially, $25 \mathrm{mg}$ of PAC was dissolved in $20 \mathrm{~mL}$ of MilliQ water to form the aqueous solution (aqueous phase). Then, $500 \mathrm{mg}$ of PLGA polymer were dissolved in 15 $\mathrm{mL}$ of dichloromethane to form the oil phase. The aqueous phase was added to the oil phase under stirring $(3,600 \mathrm{rpm})$ in a disperser (UltraTurrax) for one min to form the primary emulsion. This emulsion was added to $200 \mathrm{~mL}$ of an aqueous solution of $5 \% \mathrm{w} / \mathrm{v}$ polyvinyl alcohol (surfactant) under vigorous stirring $(24,000 \mathrm{rpm})$ for five min to form the final emulsion. Thereafter, the microparticles were isolated by centrifugation and repeated washing with distilled water to remove excess polyvinyl alcohol and the free PAC not incorporated in the PLGA matrix. Finally, the PAC/ PLGA microparticles were lyophilized (Terroni Equipamentos Científicos, model LS 3000) for 24 $\mathrm{h}$ and stored in a desiccator. This procedure was performed in duplicate.

\section{Scanning Electron Microscopy (SEM)}

The surface morphology of the PAC/PLGA microparticles was evaluated by the scanning electron microscopy technique using a PHILIPS, XL30 model electron microscope with $3.5 \mathrm{~nm}$ resolution (secondary electron mode) and an increase in the range of 4000 times, acceleration voltage $20 \mathrm{kV}$ and samples metalized with a gold thin layer. The particle size distribution of the 
microspheres was acquired by Image $\mathrm{J}$ software. 150 points of the image acquired by the SEM technique were evaluated for an estimation of the magnitude of the particle size distribution (Cocero et al., 2009)

\section{Thermogravimetric Analysis (TGA)}

Thermogravimetric analyzes were performed to determine the thermal decomposition behavior of PAC/PLGA microparticles. The thermograms were obtained using a TA Instruments SDT-Q600 equipment, in the temperature range from $25^{\circ} \mathrm{C}$ to $600^{\circ} \mathrm{C}$ with a heating rate of $10^{\circ} \mathrm{C} / \mathrm{min}$ under nitrogen atmosphere $(100 \mathrm{~mL} / \mathrm{min})$ and sample holder of platinum.

\section{Differential Scanning Calorimetry (DSC)}

The glass transition temperature of the $\mathrm{PAC} /$ PLGA microparticles was obtained by the DSC technique on TA Instruments Q20 equipment, in the temperature range from $-90^{\circ} \mathrm{C}$ to $220^{\circ} \mathrm{C}$ in two cycles (heating/cooling rate of $10^{\circ} \mathrm{C} / \mathrm{min}$ ) under nitrogen atmosphere and using a sample holder of aluminum.

\section{Fourier Transform Infrared Spectroscopy (FTIR)}

Spectroscopic analysis was carried out using Fourier transform infrared spectroscopy, Perkin Elmer Spectrum 400 model equipped with a DTGS detector and an universal attenuated total reflectance accessory (FTIR-UATR) in the spectral range of 4000-650 $\mathrm{cm}^{-1}$, with a resolution of $4 \mathrm{~cm}^{-1}$ with 32 scans.

\section{Entrapment efficiency of Proanthocyanidins (PAC)}

The entrapment efficiency of PAC in PLGA was determined by the Folin-Ciocalteu colorimetric method (Blainski et al., 2013) from supernatant solution of PAC obtained by the extraction process from PAC/PLGA microparticles. Quantification was carried out according to methodology previously described by Pool et al. (2012). The PAC percentage incorporated was determined from the initial amount of PAC less the PAC percentage found in the supernatant according to the equation below (Pool et al., 2012).

$\mathrm{EE}(\%)=\frac{\text { Total PAC in formulation }-\mathrm{PAC} \text { in supernatant }}{\text { Total PAC in formulation }} \times 100$

The Folin-Ciocalteu reagent consists of a mixture of phosphotungstic and phosphomolybdic acids which in basic medium are reduced to oxidize the PAC, yielding blue oxides, which are quantified by absorbance. Color development consists in addition of $1 \mathrm{~mL}$ of Folin-Ciocalteu reagent and $10 \mathrm{~mL}$ sodium carbonate-tartrate reagent in $50 \mathrm{~mL}$ of sample; after $30 \mathrm{~min}$ in repose the absorbance was measured. A calibration curve was done with seven points from 0.02 to $10 \mathrm{ppm}\left(\mathrm{R}^{2}=0.9981\right.$ and $\mathrm{y}=0.043 \mathrm{x}+0.0095)$ using a standard Black Wattle PAC (Tanac S/A). Absorbance measures were performed on a CELM spectrophotometer, E-225-D model at wavelength of $700 \mathrm{~nm}$ (Eaton et al., 2012).

\section{Maintenance of Cell Lines}

In this study two cell types were used, a normal cell line (Vero) and a tumor cell line (T24). The Vero cell line and human T24 tumor bladder cell line were obtained from America Type Culture Collection (ATCC - Rockville, Maryland, USA). Vero and T24 cells were grown in culture flasks in Dulbecco's Modified Eagle Medium (DMEM) or RPMI1640 culture medium, respectively, and supplemented with $10 \%(\mathrm{v} / \mathrm{v})$ of fetal bovine serum (FBS) and the antibiotics penicillin/streptomycin $0.5 \mathrm{U} / \mathrm{mL}$. Cells were seeded in 96-well plates at densities of $5 \times 10^{3}$ cells/well in a final volume of $100 \mu \mathrm{L}$ of culture medium. Cell cultures were maintained at a temperature of $37^{\circ} \mathrm{C}$, a minimum relative humidity of $95 \%$, and an atmosphere of $5 \% \mathrm{CO}_{2}$ in air. For in vitro assays, at least four independent experiments were performed in triplicate.

\section{In vitro Cytotoxicity Study}

In vitro cytotoxicities of neat PLGA and PLGA/ PAC microparticles were evaluated by measuring the viability of Vero and T24 cells in the presence of different concentrations of microparticles. Cell viability was determined by 3-(4,5-dimethylthiazol2-yl)-2,5-diphenyltetrazolium bromide, MTT assay. Twenty-four hours after plating, different amounts of PLGA and PLGA/PAC microparticles (suspend in culture medium) were added in the wells. After $24 \mathrm{~h}$ of incubation at $37^{\circ} \mathrm{C}, 100 \mu \mathrm{L}$ of MTT solution were added into each well and incubated for $3 \mathrm{~h}$. The number of cells with metabolically active mitochondria was determined based on the mitochondrial reduction of a tetrazolium bromide salt according to Nicoletti et al. (2017). The solution was immediately read on a microplate reader (SpectraMax, M2e), at a wavelength of $570 \mathrm{~nm}$. Biocompatibility and cytotoxicity of microparticles were expressed as $\%$ cell viability, which was calculated from the ratio between the number of cells treated with the microparticles and that of non-treated cells (control). 


\section{Statistical Analysis}

The number of experimental replications is provided in the figure legends. The results are presented as the mean \pm standard error mean of three groups per treatment. The statistical comparison of the data was analyzed by one-way analysis of variance followed by Tukey's posthoc test, using Graph-Pad Software (San Diego, CA, U.S.A.). $\mathrm{P}<0.05$ was indicative of statistical significance.

\section{RESULTS AND DISCUSSION}

The preparation of the PAC-loaded PLGA microparticles was successfully performed by the multiple emulsion method. Microspheres were obtained with high homogeneity of shape and size (spherical shape) without any aggregation or adhesion among them, as can be seen in Fig. 2. The particle size distributions of the PAC/PLGA microspheres (MP) are shown in Fig. 3.

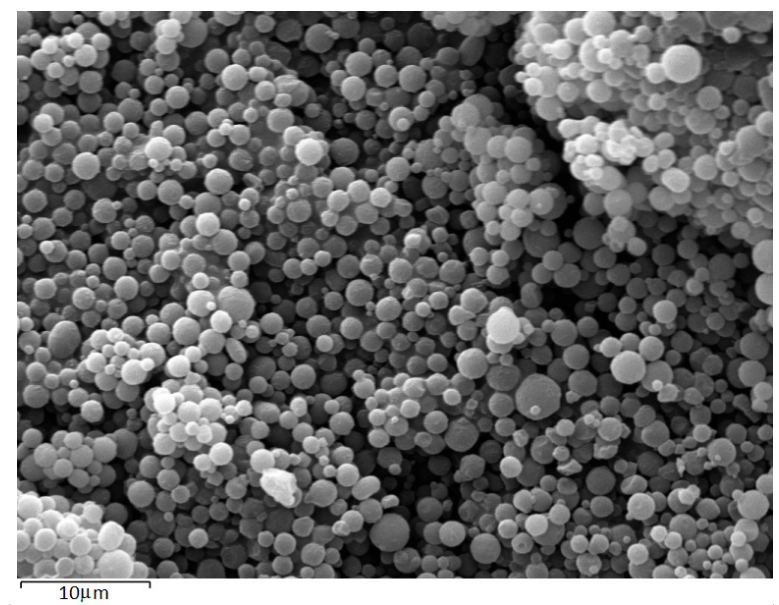

Figure 2. Micrographs of the PAC/PLGA microparticles (magnification of $4000 \mathrm{x}$ ).

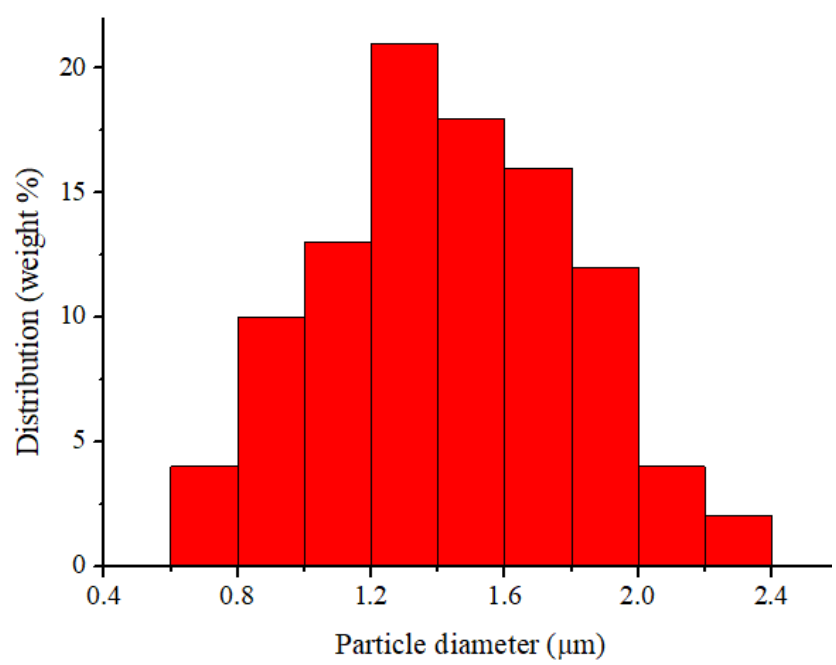

Figure 3. Particle size distribution of the PLGA/ PAC microparticles (MP).
The particle size distribution is in the range of 0.6 to $2.4 \mu \mathrm{m}$ and most of the particles have sizes between 1.2-1.8 $\mu \mathrm{m}$ confirming the obtainment of spheres in the microscale. Comparable results were found by Andry et al. (1998) for the preparation of microparticles by interfacial cross-linking of grape proanthocyanidin with terephthaloyl chloride, in which the $\mathrm{pH}$ was changed to obtain a particle size less than $10 \mu \mathrm{m}$.

Pool et al. (2012) obtained relatively small particles in the encapsulation of quercetin and catechin with PLGA. The obtained particles presented average size from 385 to $410 \mathrm{~nm}$. This result evidences that flavonoid monomers behave differently when compared to polyflavonoids. The Black Wattle PACs are composed of up to octamers, being the main fractions dimers, trimers and tetramers (Pasch et al., 2001; Venter et al., 2012). Monomers have low polarity, being poorly soluble in water, whereas polyflavonoids are very soluble in water (Grasel et al., 2016d). Molecular weight, polymer concentration, concentration and physical properties of encapsulated actives are factors that can affect the final size of the particles too (Song et al., 2008ab).

The behavior of thermal degradation for proanthocyanidin (PAC) and polyvinyl alcohol (PVA), as presented in Fig. 4, evidenced that these samples present at least two decomposition stages. A small mass loss for both, less than $6 \%$ between 0 and $150^{\circ} \mathrm{C}$, can be attributed to the vaporization of linked and non-linked water, as also observed by Arbenz and Avérous (2014). This observation can be confirmed in the DSC analysis, in which there was no evidence of any thermal event for PAC and PVA (Fig. 5).

The proanthocyanidin has a wide decomposition range mainly because it is made up of monomers to octamers with different stereochemistry and

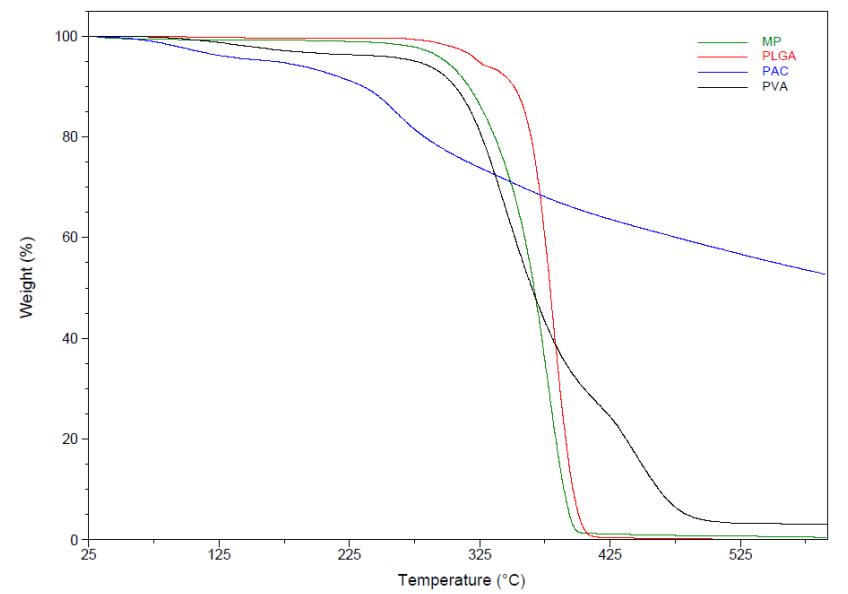

Figure 4. TG of the PAC, PVA, pristine PLGA and, PLGA/PAC microparticles (MP). 


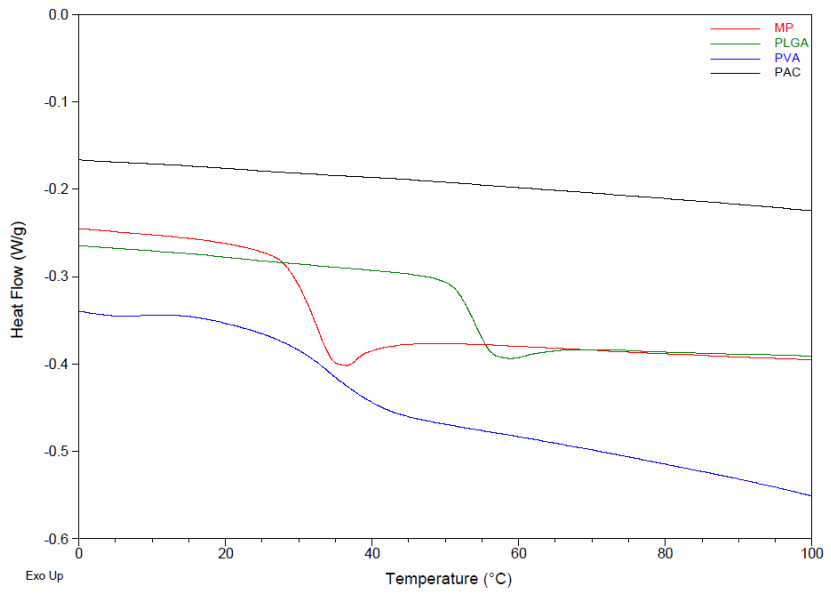

Figure 5. DSC curves of the pristine PLGA, PAC/ PLGA microparticles (MP), PVA and PAC.

replacements (Gaugler et al., 2009; Hemingway et al., 1989). The PAC sample shows a decomposition step at low temperatures (sub-ambient to $150^{\circ} \mathrm{C}$ ) that can be assigned to water loss. A second step above $150^{\circ} \mathrm{C}$ is assigned to organic matter decomposition (aromatic structures of flavonoid tannins) reaching around $55 \%$ of residue at $600^{\circ} \mathrm{C}$ (Thébault et al., 2015). These results are in agreement with those found by Arbenz and Avérous (2014) and Anwer et al. (2015) at the same conditions.

PVA also shows a wide degradation range in the range of 250 to $520^{\circ} \mathrm{C}$. As can be seen in Fig. 3, PVA presented a maximum degradation around $350{ }^{\circ} \mathrm{C}$ corresponding to $60 \%$ of mass loss and another maximum around $450^{\circ} \mathrm{C}$, attributed to the decomposition of the rest of the material, remaining $5 \%$ of residue at $600^{\circ} \mathrm{C}$. Pristine PVA exhibits more than one region of weight loss as described by other authors (Kakati et al., 2015; Yang et al., 2009).

The TGA analysis of pristine PLGA (Fig. 4) showed a weight loss of $99.3 \%$ in the range of $245-$ $433^{\circ} \mathrm{C}$, with a maximum decomposition around at $390^{\circ} \mathrm{C}$ with $0.15 \%$ residue at $600^{\circ} \mathrm{C}$. The PLGA/ PAC microparticles (MP) showed a lowest initial degradation temperature of around $180^{\circ} \mathrm{C}$, with a maximum of degradation slightly lower than pristine PLGA according to its TG curve. Similar results were also observed by Mainardes et al. (2006) when praziquantel (an antischistosome drug) was encapsulated in PLGA nanoparticles. The authors observed that praziquantel decreases the thermal stability of the nanoparticles when compared to the pure polymer.

Furthermore, the microparticles presented a higher residue percentage when compared with pristine PLGA. While the pristine PLGA presented a residue of $0.15 \%$ at $600^{\circ} \mathrm{C}$, the microparticles (PAC/PLGA) presented a residue of $0.55 \%$. This behavior is associated with the incorporation of the PAC into polymeric matrix of PLGA when compared with pristine PLGA since the PAC started thermal degradation at around $150^{\circ} \mathrm{C}$. Besides, a higher residue in the MP compared with pristine PLGA indicates the presence of a second component in MP microparticles.

In order to evaluate the presence of PAC in MP, DSC analysis was also performed. This technique is a powerful tool for investigating thermal properties, providing information about the physicochemical state (Pool et al., 2012; Seju et al., 2011). Figure 5 shows the pristine PLGA and PLGA/PAC microparticle (MP) curves obtained by the DSC technique.

The PLGA polymer exhibits an event at $56.9^{\circ} \mathrm{C}$ assigned to the glass transition temperature $\left(T_{\mathrm{g}}\right)$; no melting point is observed because this copolymer is amorphous as described elsewhere (Jose et al., 2009; Juríková et al., 2010; Motta and Duek, 2006; Park and Kang, 2013; Vasita et al., 2010). For the DSC curve of the PLGA/ PAC microparticles, a major decrease in the $T_{\mathrm{g}}$ to $35.2^{\circ} \mathrm{C}$ can be observed, suggesting that the incorporation of PAC into the PLGA matrix influences the intermolecular interactions of the copolymer chain. The crystallinity of PLGA polymer was modified during the encapsulated process because of interactions with PAC (Cocero, et al., 2009). For the pristine PAC, no thermal event is observed. It might be thought that this $T_{\mathrm{g}}$ is of the pristine PVA (since the $T_{\mathrm{g}}$ of PVA is $35^{\circ} \mathrm{C}$ ), but no melting $\left(175^{\circ} \mathrm{C}\right)$ and crystallization $\left(116^{\circ} \mathrm{C}\right)$ temperature was observed in the DSC curve of PLGA/PAC microparticles. The change in $T_{\mathrm{g}}$ was also observed in other studies with PLGA and PLA microparticles (Barras et al., 2009; Qodratnama et al., 2015). Qodratnama et al. (2015) developed large sized (100-300 $\mu \mathrm{m})$ lysozyme-loaded PLGA microparticles for tissue engineering. The authors declare that $T_{\mathrm{g}}$ close to physiological temperature will affect the viscoelastic behavior of the polymer in microparticles, influencing thereby the release kinectics of bioactive molecules. There is an increase in the molecular diffusion coefficient at temperatures above the $T_{\mathrm{g}}$ as a function of polymer mobility. The novel PLGA/PAC microparticles presented $T_{\mathrm{g}}$ of $35.2^{\circ} \mathrm{C}$ which is close to physiological temperature.

Figure 6 shows the infrared spectrum of the PLGA/PAC microparticles (MP), PAC, pristine PLGA and PVA, with the main bands highlighted.

A broad band in $3422 \mathrm{~cm}^{-1}$ assigned to $\mathrm{OH}$ stretching and in 1612 and $1505 \mathrm{~cm}^{-1}$ assigned to $\mathrm{C}=\mathrm{C}$ aromatic stretching of the $\mathrm{PAC}$ can be 


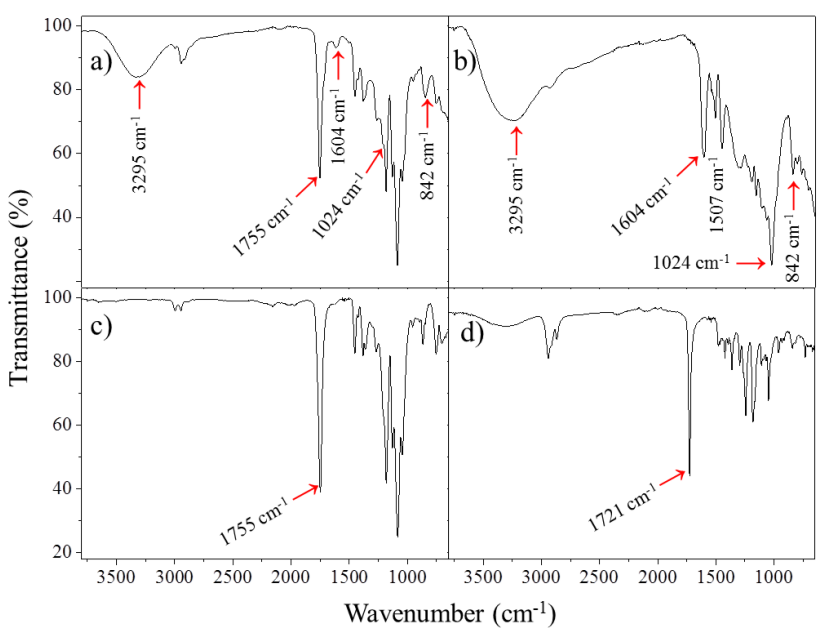

Figure 6. FTIR spectrum of a) PLGA/PAC microparticles (MP), b) PAC, c) pristine PLGA and c) PVA, with the main bands highlighted.

observed (Grasel et al., 2016c; Khan et al., 2015; Ping et al., 2012). Besides, in the fingerprint region two more vibration bands of PAC at 1210 and 846 $\mathrm{cm}^{-1}$ can be observed, which are $\mathrm{C}-\mathrm{O}$ stretching and aromatic $\mathrm{C}-\mathrm{H}$ out-of-plane bending, respectively (Grasel et al., 2016c). The bands at 2996, 2945 and $2090 \mathrm{~cm}^{-1}$ are assigned to $\mathrm{C}-\mathrm{H}$ stretching of $\mathrm{CH}_{2}$ and $\mathrm{CH}_{3}$, the first those of PLGA, the second of PLGA and PAC and third of PAC (Grasel et al., 2016c; Khan et al., 2015; Motta and Duek, 2006; Porjazoska et al., 2004; Tondi and Petutschnigg, 2015). The band at $1758 \mathrm{~cm}^{-1}$ is attributed to $\mathrm{C}=\mathrm{O}$ stretching of ester groups of the PLGA (Motta and Duek, 2006; Porjazoska et al., 2004). A band at $1451 \mathrm{~cm}^{-1}$ is relative to the signal of aromatic ring stretching of $\mathrm{PAC}$ and the asymmetrical stretching of $\mathrm{CH}$ and $\mathrm{CH}_{2}$ of PLGA (Grasel et al., 2016c; Khan et al., 2015; Motta and Duek, 2006; Porjazoska et al., 2004; Tondi and Petutschnigg, 2015). A band at $1381 \mathrm{~cm}^{-1}$ is attributed to bending $\mathrm{CH}$ and $\mathrm{CH}_{2}$ and at the region of 1263,1183 and $1045 \mathrm{~cm}^{-1}$ to $\mathrm{C}-\mathrm{O}$ stretching of pristine PLGA (Motta and Duek, 2006, Porjazoska et al., 2004).

From $1128-1045 \mathrm{~cm}^{-1}$ is the region of $\mathrm{C}-\mathrm{H}$ deformation in-plane and $754 \mathrm{~cm}^{-1}$ is assigned to $\mathrm{C}-\mathrm{H}$ deformation out-of-plane of pristine PLGA (Motta and Duek, 2006; Porjazoska et al., 2004). In the microparticles, the PAC signals can be observed at $3295 \mathrm{~cm}^{-1}, 1604 \mathrm{~cm}^{-1}$ and $842 \mathrm{~cm}^{-1}$, as well as the absence of the $\mathrm{C}=\mathrm{O}$ band of PVA at $1721 \mathrm{~cm}^{-1}$ (Alhosseini et al., 2012; Reis et al., 2006; Zeytuncu et al., 2014).

The signals in the FTIR spectrum confirm the incorporation of PAC in the PLGA microparticles.

The PAC percentage entrapment was determined from the initial amount of PAC less the percentage found in the supernatant as described by Pool et al. (2012). About $6.7 \pm 0.5 \mathrm{mg}$ of PAC was found in the supernatant, indicating that approximately $73 \%$ was incorporated into the microparticles.

Proanthocyanidins are unstable in alkaline media and high radiation (sunlight) (Grasel et al., 2017; Quideau et al., 2011). In the alkaline medium the polyflavonoids (condensed tannins) undergo rearrangement, forming phlobaphenes (red tannins) (Arbenz and Avérous, 2015). Proanthocyanidins are also sensitive to oxidation processes. The relatively weak bond dissociation energy of the phenolic $\mathrm{OH}$ bond enables the production of phenoxy radicals by hydrogen abstraction. The ability of phenols to homolytically release a hydrogen atom is also one of the fundamental processes that underlie the acclaimed health-benefiting antioxidant properties of many plant-sourced foods naturally rich in polyphenols (Quideau et al., 2011).

The encapsulation of Acacia mearnsii proanthocyanidins brings a new perspective on the application of these compounds in biological systems where there can be variations of $\mathrm{pH}$ until it gets to the target cells, guaranteeing a greater stability in their applications.

\section{Cytotoxicity of PLGA and PLGA/PAC microparticles}

Although the studied polyesters are extensively used in drug carrier applications since they are biocompatible materials (Martín-Sabroso et al., 2015; Nanaki et al., 2017; Shen et al., 2011), in the present work their cytotoxicity was compared with Acacia mearnsii proanthocyanidins loaded PLGA microparticles.

The biocompatibility and cytotoxicity of PLGA and PLGA/PAC microparticles were evaluated by MTT (Fig. 7). It was observed that in Vero and T24 lineage, PLGA and PLGA/PAC microparticles did not promote any effect on cell proliferation after 24 h. The optical density values of formazan solutions from the PLGA/PAC microparticles group were higher than those from the PLGA group after 24 h (Fig. 7); however, these differences were not statistically significant $(\mathrm{P}>0.05)$.

On the other hand, the biological properties of PAC have been studied and its cytotoxicity against tumor cells has been reported (Hostanska et al. 2007; Vaid et al. 2016; Weh et al. 2016). However, comparing the results between the controls with the treatment group wells, the non-cytotoxic profile of both microparticles can be observed. One possible explanation for this observation is the biocompatibility of PLGA and the low concentration of PAC contained within the PLGA microparticles. 


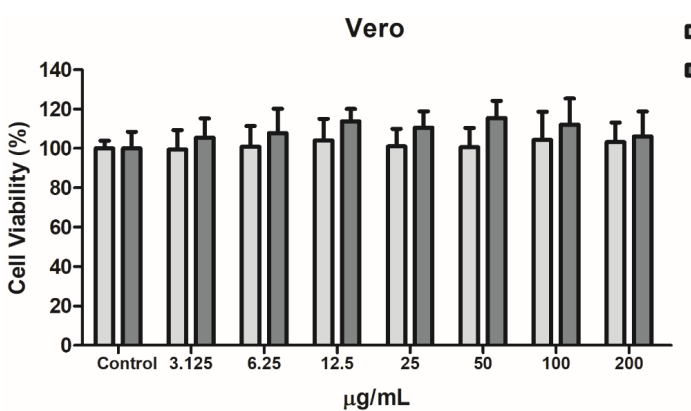

ש PLGA PLGA/PAC

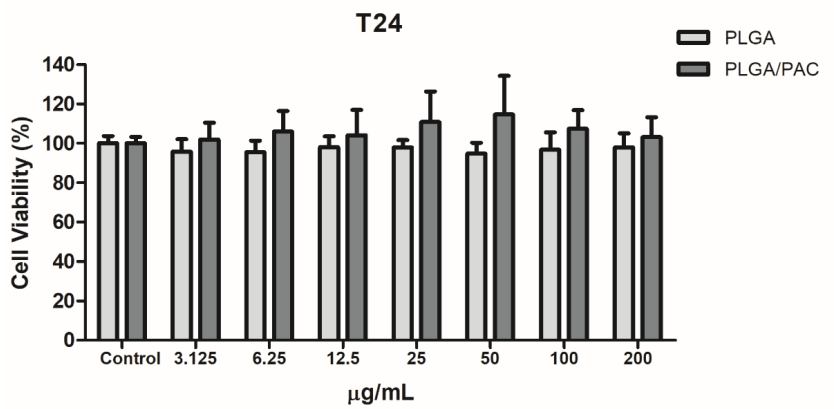

Figure 7. Evaluation of the cell viability by MTT assay, Vero and T24 cells were cultured for $24 \mathrm{~h}$ in the presence of PLGA and PLGA/PAC microparticles. The experiments were analyzed by One-way ANOVA, followed by Tukey post-hoc $(\mathrm{p}<0,005)$.

\section{CONCLUSIONS}

The multiple emulsion method was successfully used to obtain PLGA microparticles with proanthocyanidins (PAC). The initial results indicated that the obtained PLGA/PAC microparticles have spherical shape with smooth surface and average particle size between 0.6 to $2.4 \mu \mathrm{m}$. FTIR, TGA and DSC analyses of these microparticles corroborate the presence of PAC entrapped in the polymer matrix. The encapsulation efficiency was around $73 \%$. These novel PLGA/ PAC microparticles presented very interesting physical-chemistry properties with potential application in biological systems.

The results of the in vitro cytotoxicity tests in this study show the non-cytotoxic profile of PLGA and PLGA/PAC microparticles with no dose effect over the range tested. The antiproliferative properties of proanthocyanidins against cancer cells is known and reported in studies. In this study, PLGA/PAC microparticles did not promote any effect on the cellular viability at the tested concentrations after $24 \mathrm{~h}$.

The encapsulation of Acacia mearnsii proanthocyanidins brings a new perspective for the application of these compounds in biological systems, ensuring a higher resistance to oxidation and alkaline media.

\section{ACKNOWLEDGEMENTS}

The authors would like to thank TANAC S/A for financial support and PUCRS for infrastructure. $\mathrm{SE}$ and RL acknowledge CNPq for DT grant.

\section{REFERENCES}

Alhosseini, S. N., Moztarzadeh, F., Mozafari, M., Asgari, S., Dodel, M., Samadikuchaksaraei, A., Kargozar, S., Jalali, N., Synthesis and characterization of electrospun polyvinyl alcohol nanofibrous scaffolds modified by blending with chitosan for neural tissue engineering. Int. J. Nanomedicine, 7, 25-34 (2012). https://doi. org/10.2147/IJN.S25376

Andry, M. C., Vezin, H., Dumistracel, I., Bernier, J. L., Lévy, M. C., Proanthocyanidin microcapsules: preparation, properties and free radical scavenging activity. Int. J. Pharm., 171(2), 217-226 (1998). https://doi.org/10.1016/ S0378-5173(98)00183-5

Anwer, M. A., Naguib, H. E., Celzard, A., Fierro, V., Comparison of the thermal, dynamic mechanical and morphological properties of PLA-Lignin \& PLA-Tannin particulate green composites. Comp. Part B: Eng., 82, 92-99 (2015). https:// doi.org/10.1016/j.compositesb.2015.08.028

Arbenz, A., Avérous, L., Synthesis and characterization of fully biobased aromatic polyols-oxybutylation of condensed tannins towards new macromolecular architectures. RSC Adv., 4(106), 61564-61572 (2014). https://doi. org/10.1039/C4RA10691A

Arbenz, A., Avérous L., Chemical modification of tannins to elaborate aromatic biobased macromolecular architectures. Green Chem., 17(5), 2626-2646 (2015). https://doi. org/10.1039/C5GC00282F

Barras, A., Mezzetti, A., Richard, A., Lazzaroni, S., Roux, S., Melnyk, P., Betbeder, D., MonfillietteDupont, N. Formulation and characterization of polyphenol-loaded lipid nanocapsules. Int. J. Pharm., 379(2), 270-277 (2009). https://doi. org/10.1016/j.ijpharm.2009.05.054

Blainski, A., Lopes, G. C., Mello, J. C. P., Application and analysis of the Folin Ciocalteu method for the determination of the total phenolic content from Limonium Brasiliense L. Molecules, 18(6), 6852-6865 (2013). https://doi.org/10.3390/ molecules 18066852

Botha, J. J., Ferreira, D., Roux, D. G., Condensed tannins: direct synthesis, structure, and absolute configuration of four biflavonoids from black wattle bark ('mimosa') extract. J. Chem. Soc., Chem. Comm., 16, 700-702 (1978). https://doi. org/10.1039/C39780000700 
Botha, J. J., Ferreira, D., Roux, D. G., Synthesis of condensed tannins. Part 4. A direct biomimetic approach to $[4,6]$-and $[4,8]$-biflavanoids. J. Chem. Soc., Perkin. Trans I, 1235-1245 (1981). https://doi.org/10.1039/p19810001235

Cocero, M. J., Martín, Á., Mattea, F., Varona, S., Encapsulation and co-precipitation processes with supercritical fluids: fundamentals and applications. J. Supercrit. Fluids, 47(3), 546-555 (2009). https://doi.org/10.1016/j. supflu.2008.08.015

Costa, G., Lamy, E., Silva, F. C., Andersen, J., Baptista, E. S., Coelho, A. V., Salivary amylase induction by tannin-enriched diets as a possible countermeasure against tannins. J. Chem. Ecol., 34(3), 376-387 (2008). https://doi.org/10.1007/ s10886-007-9413-z

Donkora, O. N., Stojanovskaa, L., Ginnb, P., Ashtonb. J., Vasiljevica, T., Germinated grains - Sources of bioactive compounds. Food Chem., 135(3), 950-959 (2012). https://doi. org $/ 10.1016 / \mathrm{j}$. foodchem.2012.05.058

Drewes, S. E., Roux, D. G., Condensed tannins. 15. Interrelationships of flavonoid components in wattle-bark extract. Biochem. J., 87, 167-172 (1963). https://doi.org/10.1042/bj0870167

Drewes, S. E., Roux, D. G., Saayman, H. M., Eggers, S. H., Feeney, J., Some stereochemically identical biflavanols from the bark tannins of Acacia mearnsii. J. Chem. Soc. C, 1302-1308 (1967). https://doi.org/10.1039/j39670001302

Du, W. H., Peng, S. M., Liu, Z. H., Shi, L., Tan, L. F., Zou, X. Q., Hypoglycemic effect of the water extract of Pu-erh tea. J. Agric. Food. Chem., 60(40), 10126-10132 (2012). https://doi. org/10.1021/jf302426w

Eaton, A. D., Clesceri, L. S., Greenberg, A. E., Franson, M. A. H., Standard Methods for Examination of Water and Wastewater, American Public Health Association. 22 ${ }^{\mathrm{a}}$ ed. Washington, DC, 2012.

Etxeberria, U., Garza, A. L., Campión, J., Martínez, J. A., Milagro, F. I., Antidiabetic effects of natural plant extracts via inhibition of carbohydrate hydrolysis enzymes with emphasis on pancreatic alpha amylase. Expert. Opin. Ther. Tar., 16(3), 269-297 (2012). https://doi.org/10.1517/147282 22.2012 .664134

García, D. E., Glasser, W. G., Pizzi, A., Paczkowski, S. P., Laborie M.P., Modification of condensed tannins: from polyphenol chemistry to materials engineering. New J. Chem., 40(1), 36-49 (2016). https://doi.org/10.1039/C5NJ02131F

Gaugler, M., Grigsby, W. J., Thermal degradation of condensed tannins from radiata pine bark. . Wood. Chem. Technol., 29(4), 305-321 (2009). https://doi.org/10.1080/02773810903165671
Grasel, F. S., Ferrão, M.F., A rapid and non-invasive method for the classification of natural tannin extracts by near-infrared spectroscopy and PLS-DA. Anal. Methods, 8(3), 644-649 (2016). https://doi.org/10.1039/C5AY02526E

Grasel, F. S., Ferrão, M. F., Helfer, G. A., Costa, A. B., Principal Component Analysis of Commercial Tannin Extracts Using Digital Images on Mobile Devices. J. Braz. Chem. Soc., 27(12), 23722377 (2016). https://doi.org/10.5935/01035053.20160135

Grasel, F. S., Ferrão, M. F., Wolf, C. R., Ultraviolet spectroscopy and chemometrics for the identification of vegetable tannins. Ind. Crops Prod., 91, 279-285 (2016). https://doi. org/10.1016/j.indcrop.2016.07.022

Grasel, F. S., Ferrão, M. F., Wolf, C. R., Development of methodology for identification the nature of the polyphenolic extracts by FTIR associated with multivariate analysis. Spectrochim. Acta A, 153, 94-101 (2016). https://doi.org/10.1016/j. saa.2015.08.020

Grasel, F. S., Fuck, W. F., Wolf, C. R., Scheibe, E., Graeff, J. C., Costa, P.V., Development of products from Acacia mearnsii: a case of sustainability in the leather industry. Journal of AQEIC, 67(2), 13-22 (2016).

Grasel, F. S., Marcelo, M. C. A., Ferrão, M. F., Anondestructive, rapid and inexpensive methodology based on digital images for the classification of natural tannin extracts. RSC Adv., 6(38), 32358-32364 (2016). https://doi.org/10.1039/ C6RA00900J

Grasel, F. S., Marcelo, M. C. A., Ferrão, M. F., Development of inexpensive, practical and nondestructive methodology based on digital images of scanner to classification of the commercial tanning from Acacia mearnsii. Anal. Methods, 9, 3977-3982 (2017). https://doi.org/10.1039/ C7AY00945C

Hemingway, R. W., Karchesy, J. J., Chemistry and Significance of Condensed Tannins, Springer, US, 1989, p. 553. https://doi.org/10.1007/978-14684-7511-1

Hostanska, K., Jürgenliemk, G., Abel, G., Nahrstedt, A., Saller, R. Willow bark extract (BNO1455) and its fractions suppress growth and induce apoptosis in human colon and lung cancer cells. Cancer detection and prevention, 31(2), 129-139 (2007). https://doi.org/10.1016/j. cdp.2007.03.001

Hundt, H. K., Roux, D. G., Condensed tannins: determination of the point of linkage in 'terminal' $(+)$-catechin units and degradative bromination of 4-flavanylflavan-3, 4-diols. J. Chem. Soc., Chem. Comm., 16, 696-698 (1978). https://doi.org/10.1039/C39780000696 
Hundt, H. K. L., Roux, D. G., Synthesis of condensed tannins. Part 3. Chemical shifts for determining the 6- and 8-bonding positions of 'terminal of' (+)-catechin units. J. Chem. Soc., Perkin Trans 1, 1227-1234 (1981). https://doi.org/10.1039/ P19810001227

Jose, M. V., Thomas, V., Dean, D. R., Nyairo, E., Fabrication and characterization of aligned nanofibrous PLGA/Collagen blends as bonetissue scaffolds. Polymer, 50(15), 3778-3785 (2009). https://doi.org/10.1016/j.polymer.2009.05.035

Juríková, A., Csach, K., Koneracká, M., Závišová, V., Múčková, M., Tomašovičová, N., Lancz, G., Kopčanský, P., Timko, M., Miškuf, J., Magnetic polymer nanospheres for anticancer drug targeting. J. Phys.: Conf. Ser., 200(12), 122004122007 (2010). https://doi.org/10.1088/17426596/200/12/122004

Kakati, N., Maiti, J., Das, G., Lee, S. H., Yoon, Y. S., An approach of balancing the ionic conductivity and mechanical properties of PVA based nanocomposite membrane for DMFC by various crosslinking agents with ionic liquid. Int. J. Hydrogen Energ., 40(22), 7114-7123 (2015). https://doi.org/10.1016/j.ijhydene.2015.04.004

Khan, M. Y., Mangrich, A. S., Schultz, J., Grasel, F. S., Mattoso, N., Mosca, D. H., Green chemistry preparation of superparamagnetic nanoparticles containing $\mathrm{Fe}_{3} \mathrm{O}_{4}$ cores in biochar. J. Anal. Appl. Pyrol., 116, 42-48 (2015). https://doi. org/10.1016/j.jaap.2015.10.008

Kumar, V. D., Verma, P. R. P., Singh, S. K., Development and evaluation of biodegradable polymeric nanoparticles for the effective delivery of quercetin using a quality by design approach. LWT-Food Sci. Technol., 61(2), 330-338 (2015). https://doi.org/10.1016/j.lwt.2014.12.020

Kusano, R., Ogawa, S., Matsuo, Y., Tanaka, T., Yazaki, Y., Kouno, I., $\alpha$-Amylase and lipase inhibitory activity and structural characterization of acacia bark proanthocyanidins. J. Nat. Prod., 74(2), 119-128 (2010). https://doi.org/10.1021/ np100372t

Lu, W., Kelly, A. L., Miao, S., Emulsionbased encapsulation and delivery systems for polyphenols. Trends Food. Sci. Tech., 47, 1-9 (2016). https://doi.org/10.1016/j. tifs.2015.10.015

Mainardes, R. M., Gremião, M. P. D., Evangelista, R. C., Thermoanalytical study of praziquantelloaded PLGA nanoparticles. Rev. Bras. Cienc. Farm., 42, 523-530 (2006). https://doi. org/10.1590/S1516-93322006000400007

Martín-Sabroso, C., Fraguas-Sánchez, A. I., Aparicio-Blanco, J., Cano-Abad, M. F., \& Torres-Suárez, A. I. Critical attributes of formulation and of elaboration process of PLGAprotein microparticles. International journal of pharmaceutics, 480(1), 27-36 (2015). https://doi. org/10.1016/j.ijpharm.2015.01.008

Menezes, C. M., Costa, A. B., Renner, R. R., Bastos, L. F., Ferrão, M. F., Dressler, V. L., Direct determination of tannins in Acacia mearnsii bark using near-infrared spectroscopy. Anal. Methods, 6(20), 8299-8305 (2014). https://doi. org/10.1039/C4AY01558D

Motta, A. C., Duek, E. A. R., Synthesis, characterization, and" in vitro" degradation of poly (L-lactic acid-co-glycolic acid), PLGA. Matéria, 11(3), 340-350 (2006). https://doi. org/10.1590/S1517-70762006000300024

Munin, A., Edwards-Lévy, F., Encapsulation of natural polyphenolic compounds; a review. Pharmaceutics, 3(4), 793-829 (2011). https://doi. org/10.3390/pharmaceutics3040793

Nanaki, S., Siafaka, P. I., Zachariadou, D., Nerantzaki, M., Giliopoulos, D. J., Triantafyllidis, K. S., Kostoglou, M., Nikolakaki, E., Bikiaris, D. N., PLGA/SBA-15 mesoporous silica composite microparticles loaded with paclitaxel for local chemotherapy. European Journal of Pharmaceutical Sciences, 99, 32-44 (2017). https://doi.org/10.1016/j.ejps.2016.12.010

Nicoletti, N. F., Erig, T. C., Zanin, R. F., Roxo, M. R., Ferreira, N. P., Gomez, M.V; Morrone, F. B., Campos, M. Pre-clinical evaluation of voltagegated calcium channel blockers derived from the spider $\mathrm{P}$. nigriventer in glioma progression. Toxicon (Oxford), 129, 58-67 (2017). https://doi. org/10.1016/j.toxicon.2017.02.001

Olajuyigbe, O. O., Afolayan, A. J., In vitro antibacterial activities of crude aqueous and ethanolic extracts of the stem bark of Acacia mearnsii De Wild. Afr. J. Pharm. Pharmaco., 5(9), 1234-1240 (2011). https://doi.org/10.5897/ AJPP11.372

Olajuyigbe, O. O., Afolayan, A. J., Phytochemical assessment and antioxidant activities of alcoholic and aqueous extracts of Acacia mearnsii De Wild. Int. J. Pharmacol., 7(8), 856-861 (2011). https://doi.org/10.3923/ijp.2011.856.861

Olajuyigbe, O. O., Afolayan, A. J., In vitro antibacterial and time-kill assessment of crude methanolic stem bark extract of Acacia mearnsii De Wild against bacteria in shigellosis. Molecules, 17(2), 2103-2118 (2012). https://doi. org/10.3390/molecules 17022103

Olajuyigbe, O. O., Afolayan, A. J., Pharmacological assessment of the medicinal potential of Acacia mearnsii De Wild.: Antimicrobial and Toxicity activities. Int. J. Mol. Sci., 13(4), 4255-4267 (2012). https://doi.org/10.3390/ijms13044255 
Olmedo, F. G., Duran, G. S., Rins, R. S. L., Gómez, L., Royo, J., Zalduegui, P. C., Plant proteinaceous inhibitors of proteinases and alpha-amylases. In: "Oxford Surveys of Plant Molecular and Cell Biology". Oxford University Press, UK, 1987, pp. 275-334.

Pandey, S. K., Patel, D. K., Thakur, R., Mishra, D. P., Maiti, P., Haldar, C., Anti-cancer evaluation of quercetin embedded PLA nanoparticles synthesized by emulsified nanoprecipitation. Int. J. Biol. Macromol., 75, 521-529 (2015). https:// doi.org/10.1016/j.ijbiomac.2015.02.011

Park, J., Kang, S. A., study on surface, Thermal and Mechanical Properties of Absorbable PLGA Plate. Int. J. Control. Autom., 6(6), 73-82 (2013). https://doi.org/10.14257/ijca.2013.6.6.08

Pasch, H., Pizzi, A., Rode, K., MALDI-TOF mass spectrometry of polyflavonoid tannins. Polymer, 42(18), 7531-7539 (2001). https://doi. org/10.1016/S0032-3861(01)00216-6

Ping, L., Pizzi, A., Guo, Z. D., Brosse, N., Condensed tannins from grape pomace: characterization by FTIR and MALDI TOF and production of environment friendly wood adhesive. Ind. Crop. Prod., 40, 13-20 (2012). https://doi.org/10.1016/j. indcrop.2012.02.039

Pizzi, A., Celzard, A., Fierro, V., Tondi, G., Chemistry, morphology, microtomography and activation of natural and carbonized tannin foams for different applications. Macromol. Symp., 313(1), 100-111 (2012). https://doi.org/10.1002/ masy.201250311

Pool, H., Quintanar, D., Figueroa, J. D., Mano, C. M., Bechara, J. E. H., Godinez, L. A., Mendoza, S., Antioxidant Effects of Quercetin and Catechin Encapsulated into PLGA Nanoparticles, J. Nanomater., 2012, 1-12 (2012). https://doi. org/10.1155/2012/145380

Porjazoska, A., Gorecinova, K., Mladenovska, K., Glavaas, M., Simonovska, M., Janjevie, E. I., Cvetkovska, M., Poly (lactide-co-glycolide) microparticles as systems for controlled release of proteins-Preparation and characterization. Acta Pharm., 54(3), 215-229 (2004).

Qi, R., Shen, M., Cao, X., Guo, R., Tian, X., Yu, J., \& Shi, X. Exploring the dark side of MTT viability assay of cells cultured onto electrospun PLGA-based composite nanofibrous scaffolding materials. Analyst, 136(14), 2897-2903 (2011). https://doi.org/10.1039/c0an01026j

Quideau, S., Deffieux, D., Douat-Casassus, C., Pouysegu, L., Plant polyphenols: chemical properties, biological activities, and synthesis. Angew. Chem. Int. Ed., 50(3), 586-621 (2011). https://doi.org/10.1002/anie.201000044
Qodratnama, R., Serino, L. P., Cox, H. C., Qutachi, O., White, L. J., Formulations for modulation of protein release from large-size PLGA microparticles for tissue engineering. Mat. Sci. Eng. C, 47, 230-236 (2015). https://doi. org/10.1016/j.msec.2014.11.003

Reid, D. G., Bonnet, S. L., Kemp, G., van der Westhuizen, J. H., Analysis of commercial proanthocyanidins. Part 4: Solid state 13 C NMR as a tool for in situ analysis of proanthocyanidin tannins, in heartwood and bark of quebracho and acacia, and related species. Phytochemistry, 94, 243-248 (2013). https://doi.org/10.1016/j. phytochem.2013.06.007

Reis, E. F. D., Campos, F. S., Lage, A. P., Leite, R. C., Heneine, L. G., Vasconcelos, W. L., Lobato, Z. I. P., Mansur, H. S., Synthesis and characterization of poly (vinyl alcohol) hydrogels and hybrids for rMPB70 protein adsorption. Mat. Res., 9, 185-191 (2006). https://doi.org/10.1590/S151614392006000200014

Reyer, A., Tondi, G., Berger, R. J. F., Petutschnigg,A., Musso, M., Raman spectroscopic investigation of tannin-furanic rigid foams. Vib. Spectrosc., 84(11), 58-66 (2016). https://doi.org/10.1016/j. vibspec.2016.03.005

Roux, D. G., Maihs, E. A., Condensed tannins. 3. Isolation and estimation of $(-)-7: 3^{\prime}: 4^{\prime}$ : 5 '-tetrahydroxyflavan-3-ol, $(+)$-catechin and $(+)$-gallocatechin from black-wattle-bark extract. Biochem. J., 74(1), 44-49 (1960). https://doi. org/10.1042/bj0740044

Saayman, H. M., Roux, D. G., The origins of tannins and flavonoids in black-wattle barks and heartwoods, and their associatednontannin'components. Biochem. J., 97(3), 794-801 (1965). https://doi.org/10.1042/bj0970794

Sarmadi, B., Aminuddin, F., Hamid, M., Saari, N., Abdul-Hamid, A., Ismail, A., Hypoglycemic effects of cocoa (Theobroma cacao L.) autolysates. Food. Chem., 134(2), 905-911 (2012). https:// doi.org/10.1016/j.foodchem.2012.02.202

Seju, U., Kumar, A., Sawant, K. K., Development and evaluation of olanzapine-loaded PLGA nanoparticles for nose-to-brain delivery: in vitro and in vivo studies. Acta Biomet., 7(12), 4169-4176 (2011). https://doi.org/10.1016/j. actbio.2011.07.025

Shen, X., Wang, Y., Wang, F., Characterisation and biological activities of proanthocyanidins from the barks of Pinus massonian and Acacia mearnsii. Nat. Prod. Res., 24(6), 590-598 (2010). https://doi.org/10.1080/14786410903194472

Song, X., Zhao, Y., Hou, S., Xu, F., Zhao, R., He, J., Cai, Z., Li, Y., Chen, Q., Dual agents loaded PLGA nanoparticles: systematic study of particle 
size and drug entrapment efficiency. Eur. J. Pharm. Biopharm., 69(2), 445-453 (2008). https://doi.org/10.1016/j.ejpb.2008.01.013

Song, X., Zhao, Y., Wu, W., Bi, Y., Cai, Z., Chen, Q., Li, Y., Hou, S., PLGA nanoparticles simultaneously loaded with vincristine sulfate and verapamil hydrochloride: systematic study of particle size and drug entrapment efficiency. Int. J. Pharm., 350(1), 320-329 (2008). https:// doi.org/10.1016/j.ijpharm.2007.08.034

Thébault, M., Pizzi, A., Essawy, H. A., Barhoum, A., Assche, G., Isocyanate free condensed tannin-based polyurethanes. Eur. Polym. J., 67, 513-526 (2015). https://doi.org/10.1016/j. eurpolymj.2014.10.022

Tondi, G., Petutschnigg, A., Middle infrared (ATR FT-MIR) characterization of industrial tannin extracts. Ind. Crop. Prod., 65, 422-428 (2015). https://doi.org/10.1016/j.indcrop.2014.11.005

Tondi, G., Thevenon, M. F., Mies, B., Standfest, G., Petutschnigg, A., Wieland, S., Impregnation of Scots pine and beech with tannin solutions: effect of viscosity and wood anatomy in wood infiltration. Wood Sci. Technol., 47(3), 615-626 (2013). https://doi.org/10.1007/s00226-0120524-5

Vaid, M., Singh, T., Prasad, R., Katiyar, S. K. Bioactive proanthocyanidins inhibit growth and induce apoptosis in human melanoma cells by decreasing the accumulation of $\beta$-catenin. International journal of oncology, 48(2), 624-634 (2016). https://doi.org/10.3892/ijo.2015.3286

Vasita, R., Mani, G., Agrawal, C. M., Katti, D. S., Surface hydrophilization of electrospun PLGA micro-/nano-fibers by blending with Pluronic ${ }^{\circledR}$ F-108. Polymer, 51(16), 3706-3714 (2010). https://doi.org/10.1016/j.polymer.2010.05.048

Venter,P.B., Senekal, N.D., Kemp G.,Amra-Jordaan, M., Khan, P., Bonnet, S. L., van der Westhuizen, J. H., Analysis of commercial proanthocyanidins. Part 3: The chemical composition of wattle (Acacia mearnsii) bark extract. Phytochemistry, 83, 153-167 (2012). https://doi.org/10.1016/j. phytochem.2012.07.012
Viviers, P. M., Botha, J. J., Ferreira, D., Roux, D. G., Saayman, H. M., Synthesis of condensed tannins. Part 7. Angular [4,6:4,8]-prorobinetinidin triflavanoids from black wattle ('Mimosa') bark extract. J. Chem. Soc., Perkin I, 1, 17-22 (1983). https://doi.org/10.1039/P19830000017

Weh, K. M., Aiyer, H. S., Howell, A. B., Kresty, L. A. Cranberry proanthocyanidins modulate reactive oxygen species in Barrett's and esophageal adenocarcinoma cell lines. Journal of berry research, 6(2), 125-136 (2016). https:// doi.org/10.3233/JBR-160122

Wongsa, P., Chaiwarit, J., Zamaludien, A., In vitro screening of phenolic compounds, potential inhibition against $\alpha$-amylase and $\alpha$-glucosidase of culinary herbs in Thailand. Food. Chem., 131(3), 964-971 (2012). https://doi.org/10.1016/j. foodchem.2011.09.088

Xu. W., Shao, R., Xiao, J., Is There Consistency between the Binding Affinity and Inhibitory Potential of Natural Polyphenols as $\alpha$-amylase Inhibitors? Crit. Rev. Food. Sci. Nutr., 56(10), 1630-1639 (2016). https://doi.org/10.1080/1040 8398.2013.793652

Yang, J. M., Chiang, C. Y., Wang, H. Z., Yang, C. C., Two step modification of poly (vinyl alcohol) by UV radiation with 2-hydroxy ethyl methacrylate and sol-gel process for the application of polymer electrolyte membrane. J. Membr. Sci., 341(1), 186-194 (2009). https://doi. org/10.1016/j.memsci.2009.06.004

Yoshihara. E., Minho, A. P., Cardim, S. T., Tabacow, V. B. D., Yamamura, M. H., In vitro ovicidal and larvicidal activity of condensed tannins on gastrointestinal nematode infestations in sheep (Ovis aries). Semina: Ciências Agrárias, 35(6), 3173-3180 (2014). https://doi.org/10.5433/16790359.2014v35n6p3173

Zeytuncu, B., Akman, S., Yucel, O., Kahraman, M., Preparation and characterization of UVcured hybrid polyvinyl alcohol nanofiber membranes by electrospinning. Mat. Res., 17, 565-569 (2014). https://doi.org/10.1590/S151614392014005000055 